\title{
Polarization of Macrophages in Human Adipose Tissue is Related to the Fatty Acid Spectrum in Membrane Phospholipids
}

\author{
Rudolf Poledne ${ }^{1, *}$, Hana Malinska ${ }^{1}$, Hana Kubatova ${ }^{1} \mathbb{B}$, Jiri Fronek ${ }^{2}$, Filip Thieme ${ }^{2}$, \\ Sona Kauerova ${ }^{1}$ and Ivana Kralova Lesna ${ }^{1,3, *}$ \\ 1 Centre for Experimental Medicine, Institute for Clinical and Experimental Medicine, 140-21 Prague, \\ Czech Republic; hana.malinska@ikem.cz (H.M.); hana.kubatova@ikem.cz (H.K.); \\ sona.cejkova@ikem.cz (S.K.) \\ 2 Transplant Surgery Dept., Institute for Clinical and Experimental Medicine, 140-21 Prague, Czech Republic; \\ jiri.fronek@ikem.cz (J.F.); filip.thieme@ikem.cz (F.T.) \\ 3 Anaestesiology, Resuscitation and Intensive Care Unit, Military University Hospital, 140-21 Prague, \\ Czech Republic \\ * Correspondence: rudolf.poledne@ikem.cz (R.P.); ivka@ikem.cz (I.K.L.); Tel.: +420-26-136-5444 (R.P.)
}

Received: 12 November 2019; Accepted: 17 December 2019; Published: 18 December 2019

\begin{abstract}
Residential macrophages in adipose tissue play a pivotal role in the development of inflammation not only within this tissue, but also affect the proinflammatory status of the whole body. Data on human adipose tissue inflammation and the role of macrophages are rather scarce. We previously documented that the proportion of proinflammatory macrophages in human adipose tissue correlates closely with non-HDL cholesterol concentrations. We hypothesized that this is due to the identical influence of diet on both parameters and decided to analyze the fatty acid spectrum in cell membrane phospholipids of the same individuals as a parameter of the diet consumed. Proinflammatory and anti-inflammatory macrophages were isolated from human adipose tissue $(n=43)$ and determined by flow cytometry as CD14+CD16+CD36 $6^{\text {high }}$ and CD14+CD16-CD163+, respectively. The spectrum of fatty acids in phospholipids in the cell membranes of specimens of the same adipose tissue was analyzed, and the proportion of proinflammatory macrophage increased with the proportions of palmitic and palmitoleic acids. Contrariwise, these macrophages decreased with increasing alpha-linolenic acid, total n-3 fatty acids, n-3/n-6 ratio, and eicosatetraenoic acid. A mirror picture was documented for the proportion of anti-inflammatory macrophages. The dietary score, obtained using a food frequency questionnaire, documented a positive relation to proinflammatory macrophages in individuals who consumed predominantly vegetable fat and fish, and individuals who consumed diets based on animal fat without fish and nut consumption. he present data support our hypothesis that macrophage polarization in human visceral adipose tissue is related to fatty acid metabolism, cell membrane composition, and diet consumed. It is suggested that fatty acid metabolism might participate also in inflammation and the risk of developing cardiovascular disease.
\end{abstract}

Keywords: macrophages; membrane; inflammation; nutrition; omega-3 fatty acids

\section{Introduction}

Despite large-scale and successful treatment of two major risk factors of atherosclerosis, high blood pressure and high LDL cholesterol concentration, cardiovascular disease (CVD) remains the leading cause of death. This is most likely due to the continuous increase in the prevalence of obesity worldwide [1,2] and, at the same time, to visceral ectopic fat enlargement associated with increasing proinflammatory status. It has been repeatedly shown that residential macrophages in adipose tissue 
play a pivotal role in the development of inflammation not only within this tissue [3], but also influence the proinflammatory status of the whole body. Monocytes released from the spleen [4] to blood circulation are partly caught in adipose tissue, and local inflammation leading to increased immune cell migration may accelerate this process. The presence of macrophages within adipose tissue in animal experimental models has been shown to be stimulated by diets high in fat and cholesterol, and the proportion of macrophages in some of these models represented almost $40 \%$ of all adipose tissue cells [5]. It has been repeatedly proven that adipose tissue inflammation is associated with atherosclerosis progression [6]. There is a widely recognized theory that this effect is mostly indirect due to the production of adhesive and proinflammatory cytokines by residential macrophages, as well as adipocytes [7].

Catching of macrophages within adipose tissue is related to the most important risk factors of atherosclerosis and CVD. Several molecular mechanisms of the role of macrophages during the long-term process of atherogenesis have been elucidated [8]. We recently showed that the proportion of metabolically normally stimulated macrophages in human adipose tissue is positively related to body mass index (BMI) [9], age (differently in men and women) [10], and is very closely positively related to non-high-density lipoprotein HDL) cholesterol concentration [11]. On the other hand, the properties and behavior of normally stimulated proinflammatory macrophages in adipose tissue (referred to as M1) are not yet fully understood. The common cause of the very close correlation of proatherogenic lipoprotein concentrations to polarization of adipose tissue macrophages [11] might be due to the mutual effect of diet on both parameters. Next, fatty acids (FAs) in phospholipids of adipose tissue cell membranes (probably the best parameter to document long-term saturated and unsaturated FA consumption) were analyzed and correlated to the proportion of proinflammatory adipose tissue macrophages. It can also be speculated that, similar to red cells whereby insulin sensitivity [12] and inflammation [13] are directly affected by changes in the cell membrane and its FA spectrum, the role in macrophages polarization could also be influenced. Consequently, the composition of cell membrane phospholipids within adipose tissue might be related to changes in the intracellular metabolism of macrophages and their polarization.

\section{Materials and Methods}

\subsection{Living Kidney Donors}

A total of 43 individuals (enrolled between July 2014 and June 2016) were fully informed about the process of kidney donation and transplantation and about adipose tissue sampling during organ cleansing before transplantation. All individuals signed informed consent forms and were interviewed about their medical history, diet, and major cardiovascular risk factors. This project was approved by the local Ethics Committee of the Institute for Clinical and Experimental Medicine and the Faculty Thomayer Hospital on 27 June 2012 under code number 1041/12 according to the Helsinki declaration of 1975 as revised in 2000, and the study was conducted in accordance with the approved protocol.

\subsection{Tissue Samples}

Samples of visceral adipose tissue (approximately $2 \mathrm{~g}$ ) were obtained intraoperatively after hand-assisted laparoscopic nephrectomy to be immediately cooled and transferred to a laboratory. A part of these samples was used for analysis of the macrophage phenotype. Once visible blood vessels and connective tissue were removed, each sample was dissected (approximately $2 \mathrm{~mm}^{2}$ ). After shaking incubation of tissue samples with collagenase $(2 \mathrm{mg} / \mathrm{L})$ for $15 \mathrm{~min}\left(37^{\circ} \mathrm{C}\right)$, the homogenate was filtered $(50 \mu \mathrm{m})$ and centrifuged. The stromal vascular fraction (SVF) was purified twice by resuspension. The final SVF samples were analyzed immediately by flow cytometry (CyAn, Beckman Coulter, Brea, CA, USA). Only samples with viability greater than $75 \%$ were considered (measured using 7-aminoactinomycin D). Monoclonal antibodies and fluorochromes (CD14, Phycoerythrin-Cyanine, CD16, Phycoerythrin-Texas Red X (ECD), CD36, fluorescein isothiocyanate (FITC), and CD163 
Phycoerythrin, PE/Clone RM 3/1) were used to define different subsets of monocytes/macrophages. The flow cytometry data were analyzed using Kaluza software (Beckman Coulter, Brea, CA, USA).

The method was described in detail earlier [10] with definition of two phenotypes. Based on data from the literature [13-16] and our recent results [17], we proposed that macrophages with a combined phenotype characterized by the expression of CD14 and CD16 and high phagocytic receptor CD36 expression [18] correspond to normally stimulated M1 proinflammatory macrophages calling them proinflammatory adipose tissue macrophages (ATMs). On the other hand, macrophages with no CD16 expression, but with CD163 positivity, could be considered M2 [19] and were referred to as anti-inflammatory ATMs. We are well-aware that this classification could oversimplify an in vivo situation in which a full phenotypic spectrum of transient phenotypes between M1 and M2 may exist and that this situation needs to be considered. These transition fractions represent $15 \pm 2.3 \%$ of the total of macrophages within the adipose tissue of living kidney donors (LKDs) varying between 6\% and $35 \%$.

The other part of adipose tissue samples was stored at $-80^{\circ} \mathrm{C}$ and used for fatty acid (FA) analysis.

\subsection{Fatty Acid Composition}

Once all adipose tissue samples were collected and subsequently stored at $-80{ }^{\circ} \mathrm{C}$, they were removed from the freezer and slowly defrosted. The extraction, separation, and methylation of adipose tissue phospholipids were performed as previously described [18]. Total lipids were extracted with dichlormethane:methanol using a modified Folch method and phospholipids were isolated by thin-layer chromatography using hexane-diethyl ether-acetic acid (80:20:3, $v / v)$ as the solvent system. The FAs in phospholipids were converted to methyl esters using a $1 \%$ solution of $\mathrm{Na}$ in methanol. The methyl esters were eluted with hexane and separated by gas chromatography using a Hewlett-Packard GC system with hydrogen as the carrying gas, a flame ionization detector, and a carbowax-fused silica capillary column (Varian, Palo Alto, CA, USA) [19]. Individual peaks of FA methyl esters were identified by comparing retention times with those of authentic standards (mix of standard FAs, Restek Corporation, PA, USA). The proportions of FAs (a spectrum of the 18 main FAs of interest) are given as the relative percentage of the sum of FAs analyzed. The relationships of eight FAs to the macrophage phenotype were considered. The other minor FA fractions did not display any significant effect in our analysis.

\subsection{Biochemistry}

Total cholesterol, triglyceride, and HDL-cholesterol fractions were determined from fasting blood samples obtained immediately before surgery (prior to anesthesia) using an enzymatic method (Hoffmann-LaRoche, Basel, Switzerland). C-reactive protein (hsCRP) was measured by immunoturbidimetric assay using a Cobas Mira Plus autoanalyzer (Hoffmann-LaRoche, Basel, Switzerland).

\subsection{Subjects Diet Stratification}

Our simple dietary frequency questionnaire was composed of only eight questions was completed and analyzed in 39 LKDs. The diet was analyzed by a food frequency questionnaire (in Supplementary data), with special attention paid to the consumption of vegetable or animal fat for cooking and spreading, and fish and nut consumption. The highest score was obtained in individuals who consumed butter and lard for cooking, as well as for spreading (including cream/processed cheeses) on bread, but did not declare fish and nuts consumption. The lowest score was attained by individuals who declared only vegetable fat sources and very frequent consumption of fish and nuts.

\subsection{Statistical Methods}

Our data are presented as means with standard deviations for continuous variables. Categorial variables are expressed by the number of subjects. The parametric unpaired $t$-test could be 
used for continuous endpoints between LKDs and representative control because they passed the D'Agostino-Pearson normality test. The correlations of the normally distributed macrophage subpopulations and FA spectrum were documented by the coefficient of determination $\left(r^{2 \mathrm{OK}}\right)$, which was calculated with the Pearson method, including the $p$-value. All tests were two-tailed and the level of significance was set at 0.05. Statistical analyses were performed using Prism 6 (GraphPad Software, Inc., La Jolla, CA, USA).

\section{Results}

\subsection{Study Subjects}

All FA spectrum analyses were completed in 43 LKDs with a majority of maternal donors. A comparison of the characteristics of LKDs to the data of our sex- and age-matched controls selected from a representative Czech population sample [1] showed that both groups were fairly similar in all of the parameters followed (Table 1).

Table 1. Characteristics of the group of living kidney donors consisting of 27 women and 16 men and age and sex-matched controls from the $1 \%$ representative Czech population sample [1].

\begin{tabular}{ccc}
\hline & LKDs & Controls \\
\hline Age (years) & $46.30 \pm 9.87$ & $45.77 \pm 9.73$ \\
BMI $\left(\mathrm{kg} / \mathrm{m}^{2}\right)$ & $25.95 \pm 3.77$ & $27.45 \pm 6.03$ \\
Cholesterol $(\mathrm{mmol} / \mathrm{L})$ & $4.40 \pm 0.94$ & $5.43 \pm 1.09^{* * *}$ \\
HDL-cholesterol $(\mathrm{mmol} / \mathrm{L})$ & $1.16 \pm 0.38$ & $1.47 \pm 0.34^{* * *}$ \\
non-HDL-cholesterol (mmol/L) & $3.24 \pm 0.91$ & $3.96 \pm 1.08$ \\
Triglycerides (mmol/L) & $1.51 \pm 0.82$ & $1.77 \pm 1.21$ \\
hsCRP (mg/L) & $1.24 \pm 1.79$ & $1.86 \pm 2.36$ \\
Hypertension (Yes/No) & $8 / 35$ & $16 / 27$ \\
Diabetes mellitus (Yes/No) & $0 / 43$ & $3 / 40$ \\
\hline
\end{tabular}

Results are expressed as means \pm standard deviation (SD), body mass index (BMI), high-density lipoprotein, HDL, C-reactive protein (hsCRP), living kidney donors (LKDs), ${ }^{* * *} p<0.001$.

The LKDs were slightly leaner, with lower total cholesterol levels and a similar HDL/total cholesterol ratio (26.5\% for LKDs and $27.1 \%$ for controls). There were no diabetics, as diabetes mellitus is an exclusion criterion for kidney donation. The relevant population was included to document that a relatively small LKD group does not represent any selection of "more healthy" individuals. Instead, the data are valid for the general population.

\subsection{FA and ATM Relations}

The proportion of proinflammatory ATMs in the group of healthy LKDs varied from $20 \%$ to more than $60 \%$. Palmitate, as well as its desaturation product, i.e., palmitoleate, correlated positively with proinflammatory ATMs. The relation of palmitoleate was strongest among all of FA data (Figure 1). 

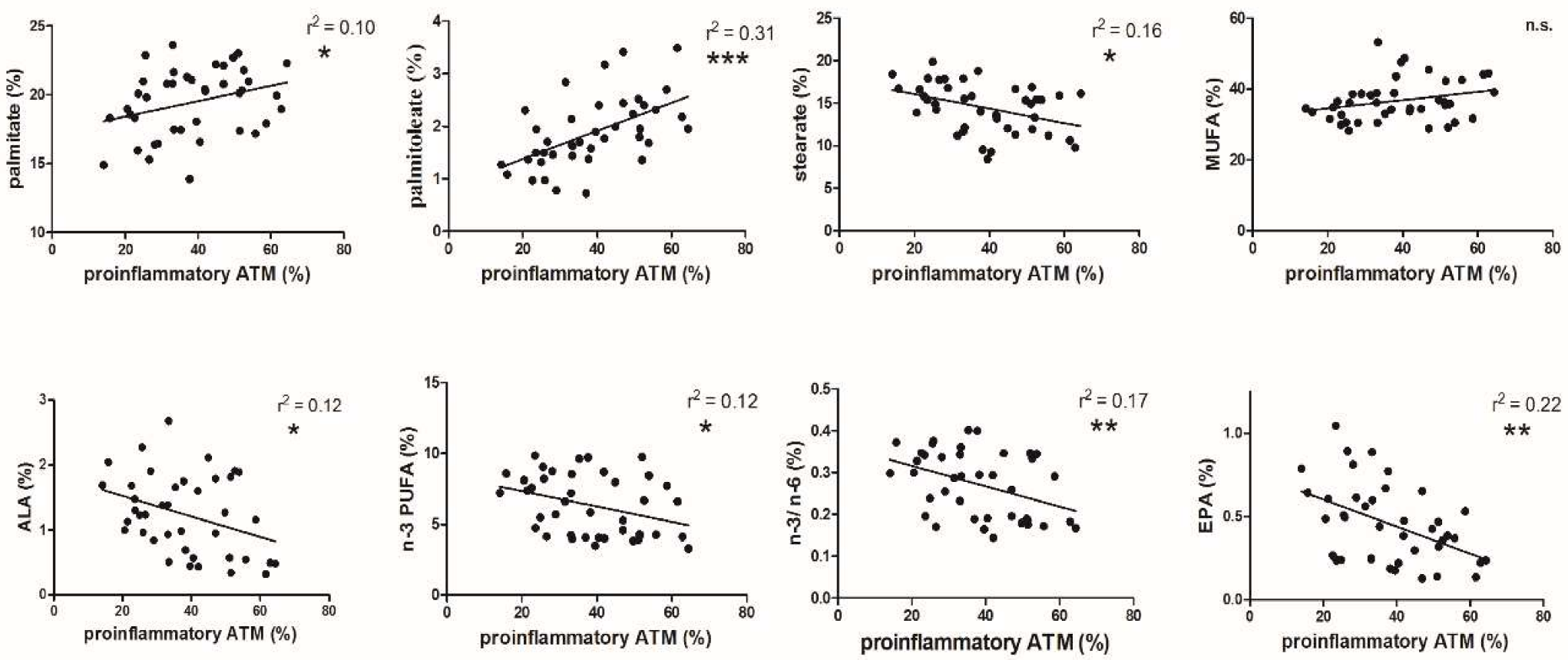

Figure 1. Correlation of the proportions of proinflammatory adipose tissue macrophages (ATMs) to different fatty acids (FAs) in phospholipids of adipose tissue cell membranes (n.s.: non significant, ${ }^{*} p<0.05 ;{ }^{* *} p<0.01$; ${ }^{* *} p<0.001$ ). alpha-linolenic acid (ALA), n-3 polyunsaturated fatty acids (n-3 FUFA), n-3 polyunsaturated fatty acids/n-6 polyunsaturated fatty acids (n-3/n-6), eicosatetraenoic acid (EPA). 
Surprisingly, an opposite, but also significant, correlation was found for stearate. Because of the opposite trend of the two most important saturated FAs on macrophage polarization, a mutual effect of all saturated FAs was not found (data no presented). No relation was found for total monounsaturated FAs (MUFAs) despite the maximum positive relation for palmitoleate itself. A negative correlation of alpha-linolenic acid (ALA) with the proportion of proinflammatory ATMs was documented, and similar significant relations were evident for total n-3 polyunsaturated FA (PUFA) and the n-3/n-6 FA ratio. As there was no relationship of n-6 FA to the proportions of proinflammatory ATMs, only the effect of n-3 FA was considered. A highly significant negative relation of the proportion of eicosatetraenoic acid (EPA) to proinflammatory ATMs was shown (Figure 1). The strength of the relation remained unchanged when performing these correlations with the exclusion of men $(n=10)$.

A mirror picture was seen for the anti-inflammatory ATMs in adipose tissue, which varied from $20 \%$ to $70 \%$ (Figure 2). No trend in the proportion of palmitate to anti-inflammatory ATMs was observed, while stearic acid was significantly positively related to anti-inflammatory ATMs. It is of interest that the effect of palmitoleic acid on the proportion of both pro- and anti-inflammatory macrophages reached the highest significance. It is also interesting that of all the MUFAs measured, this relation was found only for palmitoleate, hence there was no effect on total MUFAs. Our data did not show any relation to the proportion of ALA to anti-inflammatory ATMs. A positive correlation was demonstrated for n-3 PUFAs and the n-3/n-6 ratio to anti-inflammatory macrophages. 

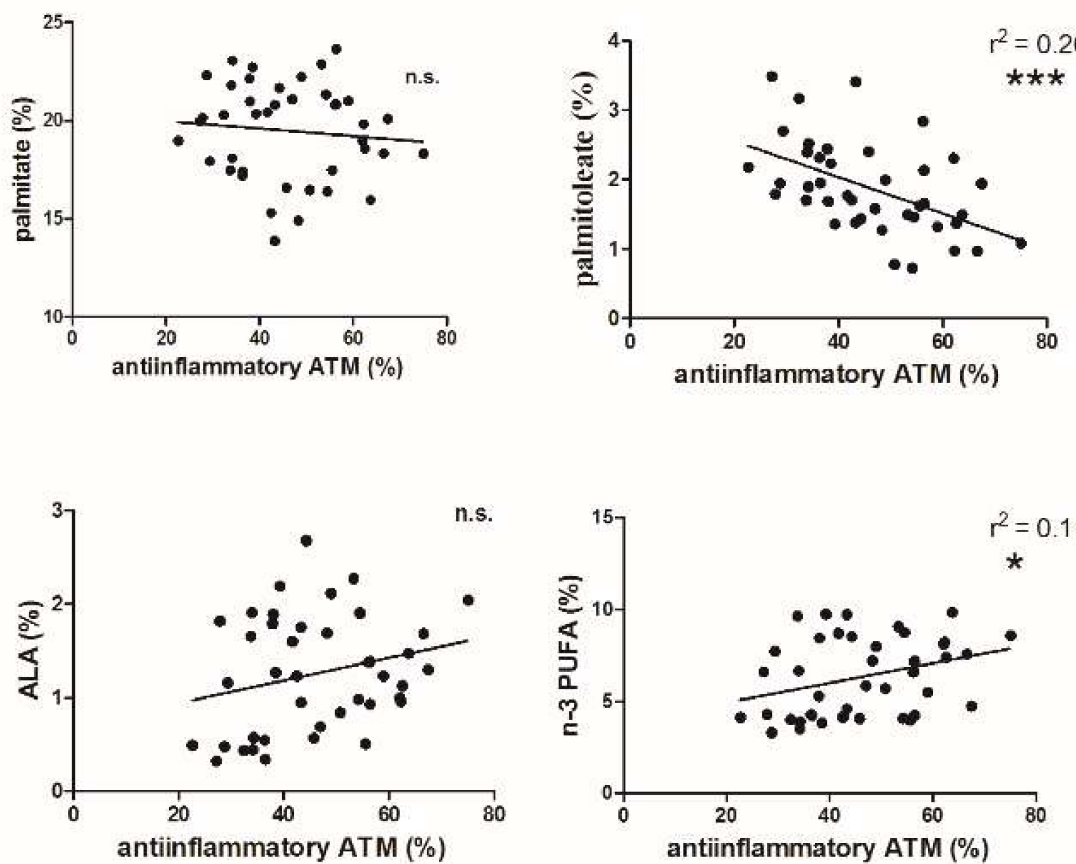
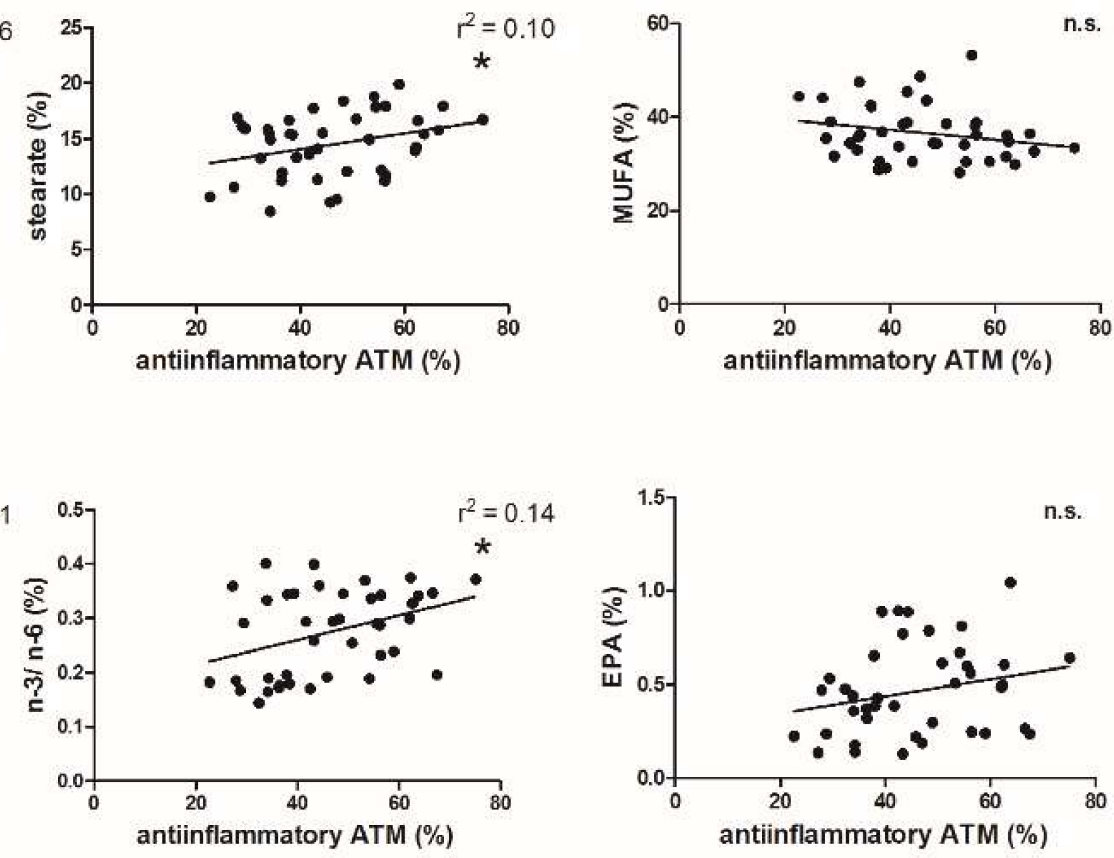

Figure 2. Correlation of the proportions of anti-inflammatory ATMs to different FAs in phospholipids of adipose tissue cell membranes $\left({ }^{*} p<0.05\right.$; $\left.{ }^{* * *} p<0.001\right)$. 
To sum up, all changes in the FA spectrum in adipose tissue phospholipids to both the pro- and anti-inflammatory ATM phenotypes (Figures 1 and 2) were interconnected.

\subsection{Dietary Score and Proinflammatory ATM Proportion}

The ratio of the dietary score to the proportion of proinflammatory ATMs and the dietary score are presented in Figure 3. The highest score, i.e., 16, was obtained in individuals who consumed butter and lard for cooking, as well as for spreading on bread, with no fish and nut consumption. The lowest score, i.e., 4 , represented individuals with only vegetable fat in their diet and very frequent consumption of fish and nuts. The dietary score of LKDs was significantly related to the proportion of proinflammatory ATMs ( $p<0.01$, Figure 3). The same opposite relation was also documented for anti-inflammatory ATMs (Supplementary Material, Figure S1).

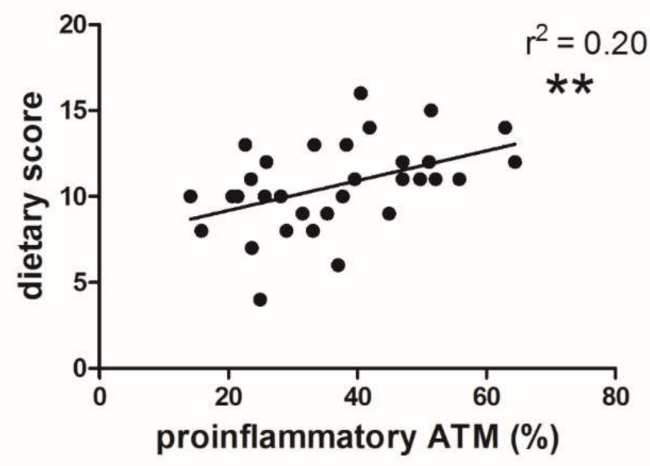

Figure 3. Correlation of the proportion proinflammatory ATMs to the dietary score $\left(n=39{ }^{* *} p<0.01\right)$.

\section{Discussion}

For over a decade, it has been known that inflammation, especially the behavior of macrophages within adipose tissue, plays a key role in the risk of developing CVD. We documented that the proportion of proinflammatory ATMs is related to the three major risk factors of atherosclerosis, i.e., age (differently in men and women), increased BMI, and non-HDL cholesterol concentration [8-10]. In this study, we analyzed ATM polarization in relation to the composition of cell membrane phospholipids of human visceral adipose tissue together with the current diet of LKDs.

The polarization of proinflammatory ATMs in the group of healthy individuals was positively related to the proportion of palmitate (Figure 1), which is in agreement with its effect in some experimental models [20,21]. Surprisingly, the effect of stearate was the opposite. Although some findings have described certain differences between the metabolism of the most common saturated FAs (SAFAs) [22], it is difficult to explain these differences based on the published data, as well as our data. As the above-mentioned two most important SAFAs exerted opposite effects, the overall effect of SAFAs was not found.

Fatty acid synthesis in macrophages has been shown to accelerate M1 polarization in tissue culture [20]. De novo synthetized FAs are incorporated into plasma membrane phospholipids and might possibly directly influence macrophage polarization [20]. The proportion of palmitate as the final product of FA synthesis might therefore cause an increase in the proportion of proinflammatory ATMs in LKDs with enhanced FA synthesis in adipose tissue. This increasing effect of macrophage polarization was also documented in experimental models with stimulated lipogenesis [23]. In principle, the different effects of palmitate and stearate on the proportion of proinflammatory ATMs might be partly explained by compartmentalization of the complex proinflammatory effects within the cell [24]. Palmitate also stimulates atherogenesis in LDL KO knock out mice, affecting reverse cholesterol transport [25], as well as increasing the production of the proinflammatory cytokines interleukin (IL)-13, monocyte chemoattractant protein-1, and IL-6. 
The most prominent correlation with proinflammatory ATMs was found in palmitoleate despite its minority within cell membrane phospholipids. The interest in this molecule has increased recently [24]. Although dietary palmitoleate intake is very low [26], it represented as much as 1-3\% of the proportion of FAs in visceral adipose tissue phospholipids of our LKDs. Palmitoleate is described as a "lipokine" with multiple regulatory roles [27]. The anti-inflammatory effect of palmitoleate was repeatedly documented in several experimental models [27-30], as was in the stimulation of insulin sensitivity (for review, see [27]). However, the effect on insulin sensitivity has not yet been confirmed in a human study [31]. All the beneficial effects of palmitoleate do not correspond to its stimulation of proinflammatory polarization in human adipose tissue in our data. This discrepancy could be explained by the substantially different effect of cis-and trans-palmitoleate reported recently [32].

Contrary to palmitate and palmitoleate, n-3 FAs had an opposite effect on macrophage polarization. An increased proportion of ALA (Figure 1) was connected with a decreased proportion of proinflammatory ATMs, with a similar effect found for total n-3 FAs and the n-3/n-6 FA ratio. This is essentially consistent with tissue culture data of the influence of n-3 PUFAs [33]. It is well-known that dietary supplemented n-3 FAs are incorporated into the plasma membrane [34] and this enrichment of the cell membrane decreases the proinflammatory status in experimental models [35], whereas n-6 FAs are not effective $[36,37]$.

The relation of increased EPA to decreasing proportion of proinflammatory ATMs was highly significant (Figure 1). This anti-inflammatory effect of EPA associated with increased fish oil intake was documented in circulatory monocytes [38]. Although this short-term experiment may not have affected adipose tissue macrophages, previous data are in agreement with our results. The increasing proportion of EPA in the cell membrane of adipose tissue is combined with decreasing polarization of proinflammatory macrophages and is essentially consistent with this FA effect in recent studies of sepsis treatment [35,39].

The proportion of proinflammatory ATMs is positively related to those of palmitic and palmitoleic acids and is a potentially proatherogenic phenomenon. A similar phagocytic phenotype was also identified in circulating monocytes [40] as CD14 and CD16 positive cells with the presence of the CD36 receptor. In 438 patients with chronic kidney disease, the expression of this molecule increased gradually with a decrease in glomerular filtration rate and predicted cardiovascular events. The fact that macrophages with this phenotype decreases with increasing proportions of ALA, n-3 FA, and EPA in our data is indirect proof of their protective role.

The effect of the proportion of FAs in cell membrane phospholipids on anti-inflammatory alternatively stimulated ATMs displayed a mirror pattern to proinflammatory ATMs, but the statistical power of the correlations was lower (Figure 2) (with the exception of a highly significant effect of palmitoleate). It should be stressed that the pro- and anti-inflammatory phenotypes do not total $100 \%$. There are also intermediary macrophages representing, on average 15\%, of total macrophages, varying between $6 \%$ and $37 \%$. This variation is probably the reason for the relatively vaguer correlation of the different FA groups to the proportion of anti-inflammatory ATMs. The strong negative relationship of palmitoleate to the proportion of anti-inflammatory ATMs supports the unusual importance of this FA in macrophage polarization in human visceral adipose tissue.

Although the positive effect of n-3 FAs on triglyceridemia, hypertension, coagulation, and arrhythmia was summarized previously [41], the association of ALA intake with coronary heart disease was definitively proved only recently [42] in a meta-analysis of 14 prospective quantitative studies. The documented effects of essential FAs (specifically ALA) correspond to the analyzed diets of our subjects. The dietary score exhibited a significant effect on the proportion of proinflammatory ATMs (Figure 3). Although our questionnaire was rather simple and focused mainly on fish and nut consumption, the significant relation of the dietary score to the proinflammatory ATM proportion supports the possibility of a direct influence of these nutrients on macrophage polarization.

A healthy diet with the recommended increase in n-3 FA is able to shift polarization of macrophages in adipose tissue to a lower proportion of proinflammatory ATMs in adipose tissue. This applies 
mainly to the proportion of ALA of individual study subjects. The most significant effect was found for EPA present in fish and nuts. Thus, the importance of diet on changing the FA spectrum in the adipose tissue cell membrane was documented despite the relatively small number of individuals studied (limited number of LKD transplant procedures performed at the Institution within one year).

Comparing the effects of individual FAs on inflammation with our results is rather difficult, as the currently available data were obtained mainly from in vitro experiments. For example, the action of oleic acid itself was found to be anti-inflammatory (analyzed by the presence of the CD206 receptor) with an inhibitory effect of palmitate [43]. Palmitate has been shown to increase IL-13 production in macrophages [44], whereas n-3 PUFAs are stimulators of anti-inflammatory molecule (resorpin and protractin) production [45]. Although the effects of individual FAs in cell membrane phospholipids of human adipose tissue are more difficult to explain, their pro- and anti-inflammatory activities are, in principle, mostly in agreement with these in vitro data.

The main limitation of our study is that the FA spectrum was analyzed in phospholipids of the cell membrane of total adipose tissue and not separately in adipocytes and macrophages. However, when comparing the amount of phospholipids in the total of adipose tissue and its SVF fraction in six individual tissue samples, SVF (including numerous different cells and macrophages) represented less than $20 \%$ of total phospholipids of adipose tissue (with minor FA proportion differences between total adipose tissue and SVF, see Supplementary Material, Table S1), so the FA spectrum represents an adipose tissue milieu and not the effect of local macrophages.

Proinflammatory polarization of ATMs by palmitate and palmitoleate and the opposite effect of ALA, n-3 FAs, n-3/n-6 FA ratio, and EPA potentially represent a new effect on the risk of developing CVD. The importance of our data obtained in human adipose tissue of healthy individuals is amplified by a similar effect of these FAs on the proinflammatory status of the whole body as measured by TNF- $\alpha$ concentration (data not shown). It should be stressed that, in addition to intracellular FA metabolism, a direct effect of diet was also documented.

\section{Conclusions}

Admittedly, the direct causality of the effect of FAs on inflammatory changes could be questioned, and an opposite effect of inflammation on the FA spectrum should be accepted. However, our data documented the effects of diet on macrophage polarization, making our conclusion more plausible. There is a potential synergy of dietary saturated FAs, which increase the LDL-cholesterol concentration and the proportion of proinflammatory ATM on the one hand, and an LDL-cholesterol-decreasing effect of n-3 polygenic FA and decreasing the proportion of proinflammatory ATMs on the other. This synergistic effect also relates to the diet consumed and might play a very important role in lifestyle changes aimed at reducing the risk of developing cardiovascular disease.

Supplementary Materials: The following are available online at http://www.mdpi.com/2072-6643/12/1/8/s1, Figure S1: Correlation of the proportion anti-inflammatory ATMs to dietary score, Table S1: Comparison of FA spectrum in adipocytes and stromal vascular fraction (\%) and Dietary questionnaire.

Author Contributions: R.P. designed the study, supervised its conduct, acquisition of data and their interpretation and drafted the manuscript. H.M. was in charge of gas chromatography analysis, S.K. performed SVF isolation and drafting of the manuscript. J.F. and F.T. performed recruitment of subjects and adipose tissue removal and contributed to critical revision of the manuscript. H.K. performed FACS analysis, data analysis and interpretation. I.K.L. participated in the study concept and design, interpretation of the data, drafting of the manuscript, and critical revision of the manuscript for important intellectual content. All authors have read and agreed to the published version of the manuscript.

Funding: The research was supported by the Ministry of Health of the Czech Republic-conceptual development of research organization (not necessary Institute for Clinical and Experimental Medicine-IKEM, IN 00023001) and by the Ministry of Health of the Czech Republic, Grant No. 17-28103A. All rights reserved.

Conflicts of Interest: The authors declare no conflict of interest. 


\section{References}

1. Cifkova, R.; Skodova, Z.; Bruthans, J.; Adamkova, V.; Jozifova, M.; Galovcova, M.; Wohlfahrt, P.; Krajcoviechova, A.; Poledne, R.; Stavek, P.; et al. Longitudinal trends in major cardiovascular risk factors in the Czech population between 1985 and 2007/8. Czech MONICA and Czech post-MONICA. Atherosclerosis 2010, 211, 676-681. [CrossRef] [PubMed]

2. Williams, E.P.; Mesidor, M.; Winters, K.; Dubbert, P.M.; Wyatt, S.B. Overweight and Obesity: Prevalence, Consequences, and Causes of a Growing Public Health Problem. Curr. Obes. Rep. 2015, 4, 363-370. [CrossRef] [PubMed]

3. Kuda, O.; Rossmeisl, M.; Kopecky, J. Omega-3 fatty acids and adipose tissue biology. Mol. Asp. Med. 2018, 64, 147-160. [CrossRef] [PubMed]

4. Mulder, R.; Banete, A.; Basta, S. Spleen-derived macrophages are readily polarized into classically activated (M1) or alternatively activated (M2) states. Immunobiology 2014, 219, 737-745. [CrossRef]

5. Weisberg, S.P.; McCann, D.; Desai, M.; Rosenbaum, M.; Leibel, R.L.; Ferrante, A.W. Obesity is associated with macrophage accumulation in adipose tissue. J. Clin. Investig. 2003, 112, 1796-1808. [CrossRef]

6. Glass, C.K.; Witztum, J.L. Atherosclerosis: The road ahead. Cell 2001, 104, 503-516. [CrossRef]

7. Ramkhelawon, B.; Hennessy, E.J.; Menager, M.; Ray, T.D.; Sheedy, F.J.; Hutchison, S.; Wanschel, A.; Oldebeken, S.; Geoffrion, M.; Spiro, W.; et al. Netrin-1 promotes adipose tissue macrophage retention and insulin resistance in obesity. Nat. Med. 2014, 20,377-384. [CrossRef]

8. Cochain, C.; Zernecke, A. Macrophages in vascular inflammation and atherosclerosis. Pflügers Arch. 2017, 469, 485-499. [CrossRef]

9. Lesna, I.K.; Cejkova, S.; Kralova, A.; Fronek, J.; Petras, M.; Sekerkova, A.; Thieme, F.; Janousek, L.; Poledne, R. Human adipose tissue accumulation is associated with pro-inflammatory changes in subcutaneous rather than visceral adipose tissue. Nutr. Diabetes 2017, 7, e264. [CrossRef]

10. Kralova Lesna, I.; Poledne, R.; Fronek, J.; Kralova, A.; Sekerkova, A.; Thieme, F.; Pitha, J. Macrophage subsets in the adipose tissue could be modified by sex and the reproductive age of women. Atherosclerosis 2015, 241, 255-258. [CrossRef]

11. Poledne, R.; Kralova Lesna, I.; Kralova, A.; Fronek, J.; Cejkova, S. The relationship between non-HDL cholesterol and macrophage phenotypes in human adipose tissue. J. Lipid Res. 2016, 57, 1899-1905. [CrossRef] [PubMed]

12. Min, Y.; Lowy, C.; Islam, S.; Khan, F.S.; Swaminathan, R. Relationship between red cell membrane fatty acids and adipokines in individuals with varying insulin sensitivity. Eur. J. Clin. Nutr. 2011, 65, 690-695. [CrossRef] [PubMed]

13. Muralidharan, J.; Papandreou, C.; Sala-Vila, A.; Rosique-Esteban, N.; Fito, M.; Estruch, R.; Angel Martinez-Gonzalez, M.; Corella, D.; Ros, E.; Razquin, C.; et al. Fatty Acids Composition of Blood Cell Membranes and Peripheral Inflammation in the PREDIMED Study: A Cross-Sectional Analysis. Nutrients 2019, 11, 576. [CrossRef] [PubMed]

14. Aron-Wisnewsky, J.; Tordjman, J.; Poitou, C.; Darakhshan, F.; Hugol, D.; Basdevant, A.; Aissat, A.; Guerre-Millo, M.; Clement, K. Human adipose tissue macrophages: $\mathrm{m} 1$ and $\mathrm{m} 2$ cell surface markers in subcutaneous and omental depots and after weight loss. J. Clin. Endocrinol. Metab. 2009, 94, 4619-4623. [CrossRef]

15. Barros, M.H.; Hauck, F.; Dreyer, J.H.; Kempkes, B.; Niedobitek, G. Macrophage polarisation: An immunohistochemical approach for identifying M1 and M2 macrophages. PLoS ONE 2013, 8, e80908. [CrossRef]

16. Kovacikova, M.; Sengenes, C.; Kovacova, Z.; Siklova-Vitkova, M.; Klimcakova, E.; Polak, J.; Rossmeislova, L.; Bajzova, M.; Hejnova, J.; Hnevkovska, Z.; et al. Dietary intervention-induced weight loss decreases macrophage content in adipose tissue of obese women. Int. J. Obes. 2011, 35, 91-98. [CrossRef]

17. Kralova Lesna, I.; Kralova, A.; Cejkova, S.; Fronek, J.; Petras, M.; Sekerkova, A.; Thieme, F.; Janousek, L.; Poledne, R. Characterisation and comparison of adipose tissue macrophages from human subcutaneous, visceral and perivascular adipose tissue. J. Tansl. Med. 2016, 14, 208. [CrossRef]

18. Malinska, H.; Huttl, M.; Oliyarnyk, O.; Bratova, M.; Kazdova, L. Conjugated linoleic acid reduces visceral and ectopic lipid accumulation and insulin resistance in chronic severe hypertriacylglycerolemia. Nutrition 2015, 31, 1045-1051. [CrossRef] 
19. Eder, K. Gas chromatographic analysis of fatty acid methyl esters. J. Chromatogr. B Biomed. Appl. 1995, 671, 113-131. [CrossRef]

20. Menegaut, L.; Thomas, C.; Lagrost, L.; Masson, D. Fatty acid metabolism in macrophages: A target in cardio-metabolic diseases. Curr. Opin. Lipidol. 2017, 28, 19-26.

21. Thomas, D.; Apovian, C. Macrophage functions in lean and obese adipose tissue. Metabolism 2017, 72, 120-143. [CrossRef] [PubMed]

22. Poledne, R. Inflammation and atherogenic effects due to saturated fatty acids. In Handbook of Lipids in Human Function: Fatty Acids; Watson, R.R., De Meester, F., Eds.; AOCS Press, Elsevier: Amsterdam, The Netherlands, 2016; pp. 163-179.

23. Ecker, J.; Liebisch, G.; Englmaier, M.; Grandl, M.; Robenek, H.; Schmitz, G. Induction of fatty acid synthesis is a key requirement for phagocytic differentiation of human monocytes. Proc. Natl. Acad. Sci. USA 2010, 107, 7817-7822. [CrossRef] [PubMed]

24. Hodson, L.; Karpe, F. Is there something special about palmitoleate? Curr. Opin. Clin. Nutr. Metab. Care 2013, 16, 225-231. [CrossRef] [PubMed]

25. Afonso, M.S.; Lavrador, M.S.; Koike, M.K.; Cintra, D.E.; Ferreira, F.D.; Nunes, V.S.; Castilho, G.; Gioielli, L.A.; Paula Bombo, R.; Catanozi, S.; et al. Dietary interesterified fat enriched with palmitic acid induces atherosclerosis by impairing macrophage cholesterol efflux and eliciting inflammation. J. Nutr. Biochem. 2016, 32, 91-100. [CrossRef]

26. Knutsen, S.F.; Fraser, G.E.; Beeson, W.L.; Lindsted, K.D.; Shavlik, D.J. Comparison of adipose tissue fatty acids with dietary fatty acids as measured by 24-hour recall and food frequency questionnaire in Black and White Adventists: The Adventist Health Study. Ann. Epidemiol. 2003, 13, 119-127. [CrossRef]

27. Frigolet, M.E.; Gutierrez-Aguilar, R. The Role of the Novel Lipokine Palmitoleic Acid in Health and Disease. Adv. Nutr. 2017, 8, 173S-181S. [CrossRef]

28. Chan, K.L.; Pillon, N.J.; Sivaloganathan, D.M.; Costford, S.R.; Liu, Z.; Theret, M.; Chazaud, B.; Klip, A. Palmitoleate Reverses High Fat-induced Proinflammatory Macrophage Polarization via AMP-activated Protein Kinase (AMPK). J. Biol. Chem. 2015, 290, 16979-16988. [CrossRef]

29. Foryst-Ludwig, A.; Kreissl, M.C.; Benz, V.; Brix, S.; Smeir, E.; Ban, Z.; Januszewicz, E.; Salatzki, J.; Grune, J.; Schwanstecher, A.K.; et al. Adipose Tissue Lipolysis Promotes Exercise-induced Cardiac Hypertrophy Involving the Lipokine C16:1n7-Palmitoleate. J. Biol. Chem. 2015, 290, 23603-23615. [CrossRef]

30. Yang, Z.H.; Pryor, M.; Noguchi, A.; Sampson, M.; Johnson, B.; Pryor, M.; Donkor, K.; Amar, M.; Remaley, A.T. Dietary Palmitoleic Acid Attenuates Atherosclerosis Progression and Hyperlipidemia in Low-Density Lipoprotein Receptor-Deficient Mice. Mol. Nutr. Food Res. 2019, 63, e1900120. [CrossRef]

31. Gong, J.; Campos, H.; McGarvey, S.; Wu, Z.; Goldberg, R.; Baylin, A. Adipose tissue palmitoleic acid and obesity in humans: Does it behave as a lipokine? Am. J. Clin. Nutr. 2011, 93, 186-191. [CrossRef]

32. Cimen, I.; Yildirim, Z.; Dogan, A.E.; Yildirim, A.D.; Tufanli, O.; Onat, U.I.; Nguyen, U.; Watkins, S.M.; Weber, C.; Erbay, E. Double bond configuration of palmitoleate is critical for atheroprotection. Mol. Metab. 2019. [CrossRef] [PubMed]

33. De Boer, A.A.; Monk, J.M.; Liddle, D.M.; Power, K.A.; Ma, D.W.; Robinson, L.E. Fish Oil-Derived Long-Chain n-3 Polyunsaturated Fatty Acids Reduce Expression of M1-Associated Macrophage Markers in an ex vivo Adipose Tissue Culture Model, in Part through Adiponectin. Front. Nutr. 2015, 2, 31. [CrossRef] [PubMed]

34. Venkatraman, J.T.; Toohey, T.; Clandinin, M.T. Does a threshold for the effect of dietary omega-3 fatty acids on the fatty acid composition of nuclear envelope phospholipids exist? Lipids 1992, 27, 94-97. [CrossRef] [PubMed]

35. Calder, P.C. Omega-3 fatty acids and inflammatory processes: From molecules to man. Biochem. Soc. Trans. 2017, 45, 1105-1115. [CrossRef] [PubMed]

36. Colson, C.; Ghandour, R.A.; Dufies, O.; Rekima, S.; Loubat, A.; Munro, P.; Boyer, L.; Pisani, D.F. Diet Supplementation in omega3 Polyunsaturated Fatty Acid Favors an Anti-Inflammatory Basal Environment in Mouse Adipose Tissue. Nutrients 2019, 11, 438. [CrossRef]

37. Browning, L.M.; Walker, C.G.; Mander, A.P.; West, A.L.; Madden, J.; Gambell, J.M.; Young, S.; Wang, L.; Jebb, S.A.; Calder, P.C. Incorporation of eicosapentaenoic and docosahexaenoic acids into lipid pools when given as supplements providing doses equivalent to typical intakes of oily fish. Am. J. Clin. Nutr. 2012, 96, 748-758. [CrossRef] 
38. Hagi, A.; Nakayama, M.; Shinzaki, W.; Haji, S.; Ohyanagi, H. Effects of the omega-6: Omega-3 fatty acid ratio of fat emulsions on the fatty acid composition in cell membranes and the anti-inflammatory action. JPEN J. Parenter. Enter. Nutr. 2010, 34, 263-270. [CrossRef]

39. Yaqoob, P.; Pala, H.S.; Cortina-Borja, M.; Newsholme, E.A.; Calder, P.C. Encapsulated fish oil enriched in alpha-tocopherol alters plasma phospholipid and mononuclear cell fatty acid compositions but not mononuclear cell functions. Eur. J. Clin. Investig. 2000, 30, 260-274. [CrossRef]

40. Manzanares, W.; Langlois, P.L.; Dhaliwal, R.; Lemieux, M.; Heyland, D.K. Intravenous fish oil lipid emulsions in critically ill patients: An updated systematic review and meta-analysis. Crit. Care 2015, 19, 167. [CrossRef]

41. Rogacev, K.S.; Zawada, A.M.; Emrich, I.; Seiler, S.; Bohm, M.; Fliser, D.; Woollard, K.J.; Heine, G.H. Lower Apo A-I and lower HDL-C levels are associated with higher intermediate CD14++CD16+ monocyte counts that predict cardiovascular events in chronic kidney disease. Arterioscler. Thromb. Vasc. Biol. 2014, 34, 2120-2127. [CrossRef]

42. Kris-Etherton, P.M.; Harris, W.S.; Appel, L.J. Fish consumption, fish oil, omega-3 fatty acids, and cardiovascular disease. Circulation 2002, 106, 2747-2757. [CrossRef] [PubMed]

43. Wei, J.; Hou, R.; Xi, Y.; Kowalski, A.; Wang, T.; Yu, Z.; Hu, Y.; Chandrasekar, E.K.; Sun, H.; Ali, M.K. The association and dose-response relationship between dietary intake of alpha-linolenic acid and risk of CHD: A systematic review and meta-analysis of cohort studies. Br. J. Nutr. 2018, 119, 83-89. [CrossRef] [PubMed]

44. Camell, C.; Smith, C.W. Dietary oleic acid increases $\mathrm{m} 2$ macrophages in the mesenteric adipose tissue. PLoS ONE 2013, 8, e75147. [CrossRef] [PubMed]

45. Robblee, M.M.; Kim, C.C.; Porter Abate, J.; Valdearcos, M.; Sandlund, K.L.; Shenoy, M.K.; Volmer, R.; Iwawaki, T.; Koliwad, S.K. Saturated Fatty Acids Engage an IRE1alpha-Dependent Pathway to Activate the NLRP3 Inflammasome in Myeloid Cells. Cell Rep. 2016, 14, 2611-2623. [CrossRef]

(C) 2019 by the authors. Licensee MDPI, Basel, Switzerland. This article is an open access article distributed under the terms and conditions of the Creative Commons Attribution (CC BY) license (http://creativecommons.org/licenses/by/4.0/). 